\title{
Interview: The Importance of Investigation: An Interview With Jack Sava, MD
}

\author{
Nikhil Chervu ${ }^{1}$ \\ ${ }^{1}$ Medicine, Georgetown University (DC) \\ Keywords: medical students, faculty, medical research, interview \\ https://doi.org/10.52504/001c.3402
}

\section{Georgetown Medical Review}

Vol. 2, Issue 1, 2018

An interview with Jack Sava, MD, general surgery residency program director and chief of trauma surgery at MedStar Washington Hospital Center.

I recently sat down with Jack Sava, MD, who serves as the general surgery residency program director and chief of trauma surgery at MedStar Washington Hospital Center. We discussed his research interests, the importance of research as a medical student, and the relationship between Halloween decorations and candy bar size. The author thanks Dr. Sava for his time and generosity in sharing his knowledge with GMR. (Interview edited for clarity and length.)

Chervu: Would you introduce yourself?

Dr. Sava: I'm Jack Sava. I'm the residency program director at MedStar Washington Hospital Center and the chief of trauma.

\section{C: Do you have any particular research interests?}

S: Well, that's a good overall question. An embedded question in that is whether people should be extremely narrow in their focus of research or whether they should be broad. I think that the general agreement is that people are more successful when they are narrow and focused and pick a small thing and work at it over a number of years. My motives for doing research are many and varied. For me, it's important to be able to pick a variety of questions and either answer them or help people answer them for intellectual reasons or for teaching reasons, even though that may not be the sort of stellar pathway to research career success. Having said that, the thing that I would most like to pursue, and where I think I have the most to offer, is in the area of the impact of stress on hyperacute medical decision making, and I mean caregiver stress, more aptly, caregiver fear. Because I think that's an underreported phenomenon, despite being considered critical in other fields such as police, military, athletics, and so forth.

C: So, do you think then that physicians should broaden their research scope in general? You have a lot of PhDs who are very focused on narrow, individual topics. Do you think that in order to be a good physician-researcher, you should be willing to expand your research interests? 
S: No, I wouldn't say that, and I don't think I can engage with the label of "good physician-researcher" because I don't know whether that's something that I want to be or don't want to be. It's an undefined thing to me. But I think that if your goal is to climb academic ladders, then most certainly you should stay narrow, and I think that, in many cases, to make a big impact on changing management of something probably requires multiple, progressive attacks on a topic. And more practically speaking, that often means a pilot study that's used to help to obtain funding, and then a series of questions related to a core question. So, I'm all for that general process, I just think that there are some other research missions that need not be lost in the pursuit towards that. The world is generally, I think, consolidating on the idea that research and research funding should be consolidated in the hands of a few people who do a whole bunch of it in a very focused way, and I'm okay with that. I just think it's also a critical skill and a critical process for these other reasons that I've eluded to. I always think of one project that Laura Johnson [MD, burn attending at MedStar Washington Hospital Center] did when she was a resident here. We were thinking of a couple patients who had a high bilirubin, and we did a test and they all turned out to be negative. We just wondered, "Well, how often does that happen? Do we need to do all these tests?" So, we looked at 50 patients after trauma who were sitting in the ICU and developed a high bilirubin, and there were no consequences to any of the expensive tests we did. So, the thing that I thought was so beautiful about that was the idea of a couple people noticing a phenomenon and saying, "Let's think more rigorously think about this. Let's look at a sample size where we can actually come to a conclusion." And that idea of just wanting to take a thing you're curious about and try to answer it in a more meaningful way, rather than just shrug your shoulders and swapping anecdotes, is to me a very beautiful thing. It doesn't matter to me whether that makes you famous or gets published, and it doesn't really matter, necessarily, if it goes on and changes anybody's practice. It's just a more rigorous way of doing what human beings do in their routine life. And the fact is, I do that in my home life! Two years ago, my kids and I went trick-or-treating and we graphed the relationship between external décor and candy load giving based on a hypothesis that a lot of people who were putting a lot of effort in having the fanciest outdoor décor were not ponying up in terms of multiple, desirable candy bars.

\section{C: Really? Inverse relationship?}

S: Yeah! In fact, it was mainly a scatterplot, which was not quite an inverse relationship, but still interesting to know. So we didn't publish that result [laughs], but I thought that I taught my kids something about, well, if you're curious about something-

C: You investigate it. 
S: Yeah! You can chat about it or gather a little bit of data. I did the same thing with my daughter about what evening feeding schedule led to her sleeping through the night. And I'm not a crazy wacko life-hacker, where I do this all day long [laughs]. But when you get to the point where you're giving a fair amount of thought to something, I think it's a beautiful thing to ask yourself, "Well, how can I really answer that question?"

C: How important do you think it is then for medical students to be involved in research? Residency applications are getting more complicated. There's a lot of talk about you need $x$ amount of publications in order to be accepted in to a top residency program. How important do you think research is for med students to pursue?

S: You know, I mentioned there's a number of reasons to do research. One of the fascinating things that almost pertains more to senior faculty members than to students, although it's relevant to both, is the idea of research as a currency of advancement. And, I think personally the world has chosen research productivity as currency of advancement, say, from student to resident or from associate professor to full professor. And I think the world has decided on that for kind of crafty, effective reasons because research brings out the innate laziness or procrastinator in all of us like nothing else really. And research projects develop these hurdles and these frustrations that defeat most people. And so, I'm not sure whether I'm super happy that the world has decided that this is a hard-wired currency that you need to acquire if you want to advance, but it's not that dumb. I mean, in terms of pushing through on a project that has become very frustrating, when you're tired and all that, it is a good metric for that. So, all of that is by way of saying that for students, I think that people are looking to see whether or not people have that ability. Now, it's not a perfect metric, and also people can push through with other metrics, but especially if you plan to go to an academic residency or have any sort of academic career, then people are going to look at that metric. And I think the thing that I always say is, the first thing that people look for is some versus none.

And then much later in the process, they might look at more versus less or good versus bad. But having the goose egg under your publications, you know, bold underline publications and underneath it, blank white paper, that's the first thing that you want to avoid.

\section{C: "Coming Attraction" or "To Be Determined?"}

S: [Laughs] Yeah, exactly. Now, that doesn't get at the question of what other reasons would we want learners and trainees to be exposed to research for. You won't hear this anywhere else, but my feeling is that someone who has never done a bit of research and developed a familiarity with research methodology should never read the literature, the primary medical literature. They should read review articles, expert opinion, and maybe meta-analyses and book 
chapters. It is dangerous for somebody who doesn't have any familiarity with that to read a paper by some group in Ohio about some therapy. Because they don't have the skills to apply; they're going to come to a dangerous conclusion.

C: Well, I don't think that's unfounded. We take a lot of classes teaching us statistical methods and it's amazing, I mean, the difference between relative risk and an odds ratio based on sample size. Those are 2 very different things. Somebody interpreting it could draw the wrong correlations.

S: But even on a more subjective level, once you've done a number of types of studies, you can look at someone else's and immediately sort of know, just from the way they write it, "Oh, here's what happened" or "Here's the part of this study that we probably can believe, but clearly they didn't really have their act together on this other part." One of the most important things, a fascinating fact in life, is that somebody can study a therapy and have it work and then another person studies the same therapy and it doesn't work. But for most of us reading it for the first time, it reads like, "Well, this thing works!" You can't imagine that somebody would do another study, another person with integrity, and come to an opposite conclusion. You have to live that a few times to appreciate why you don't necessarily believe the first study on a topic.

C: Sure, we see the phenomenon with anti-vaccine proponents. Andrew Wakefield's paper was published and many people began linking vaccines to autism after that paper.

And nobody has ever reproduced it.

S: And that idea of reproducibility sounds kind of "nerdy" and unnecessary until you live through these things. I guess the correlate is, it's always super amazing how things that work in rats don't work in humans. I mean, if you think of the articles on the front page of the New York Times or the Post about something that's stopped cancer in rats, everybody's like, "Okay, I guess we got cancer licked!” Without knowing anything about the article, anything about the therapy, I'm the only one in the room who's like, "Ugh, okay, I doubt it. Possible, but I doubt it." And so that's another thing, you have to viscerally appreciate it by doing it yourself or becoming intimate with those types of studies.

C: So, when did you start actively doing research? Did you start as a med student or resident? High school?

S: I feel like my pathway is strange. It's not one I'm proud of because I'd like to think of myself as some sort of self-driven, autonomous thinker. I did essentially none in residency, a little bit, maybe. None whatsoever in med school. I have no idea why. Other people were. I just had my head in the sand. It wasn't, I guess, served properly on a silver platter to me, so I didn't partake. And in residency, it wasn't culturally important in my residency, so I did almost none. Suddenly, I went to fellowship; everybody was doing it, 
and, like a lemming, I suddenly did a whole bunch of it [laughs]. I wish it were otherwise. I proved that we're all susceptible to what the culture supports wherever you are, and maybe there's some element of "I don't want to be doing less than that person next to me." It's a little bit of innate competitiveness that I also thought I didn't have, but the facts speak otherwise [laughs].

\section{C: Do you read any journals on a regular basis?}

S: Yeah, I do. I read a number of them, but I found that there's this inherent competition between the strategy of just reading stuff when it comes out no matter what and intensely reading about topics that come up in my clinical or scholarly life. And there's no question that the latter strategy is more fun and satisfying. I think that as I get older, my kind of scout reading of things that come up is more, because I don't want to miss the next big thing that's super important. I don't want to be that guy who's still giving the therapy that was disproven last year. So, it's almost his fear-based, looking around looking really stupid. But, I think that in terms of adult learning, what will stick with you is when you have a diverticulitis case, and you take the opportunity to read everything that's come up in the last 10 years on diverticulitis and you synthesize it. I take these kinds of exhaustive notes that I keep on an ongoing basis, and that's what they're doing for you guys in med school now. It's casebased, and the main reason is because it's so much more "sticky" in the long run. So, I've definitely found that my brain does much better at that than at any sort of broad, general skim-reading, but I feel an obligation to do some of both. [Points to desk] You can see my stack of unread journals there, speaks to my success in the former [laughs].

C: The last question I have is, what do you think are the current trends or hot topics in trauma and general surgical research?

S: Well, trauma and general surgery are very different. Over the last 10 or 20 years, in trauma, the question of what fluid and how much to give has been the focus of much or most of basic science research and some clinical research also. That trend has generally been from normal saline towards other stuff, and so people are still bickering about the merits of both blood and nonblood fluids to give. I think that in terms of resuscitating bleeding people, probably the general topic of giving fibrinolysis is a hot topic because we're all in the country giving antifibrinolytics, like tranexamic acid, pretty aggressively. The big studies suggest that it decreases mortality in some subset of patients, but the latest thoughts are that maybe some patients who are hyperfibrinolytic benefit from it, others who are in fibrinolysis shut down and are actually harmed by it, and then some in the middle have no effect. That's interesting because it's sort of analogous to the way we think of all medicine, that actually maybe we need to find out more specifically which patients benefit from stuff.

C: As opposed to giving it to everybody? 
S: Yeah, and then discard it if many people benefit and then some don't. And on balance, it's neutral, then we just discard those medications historically. Maybe we need to do a better job of personalized medicine, figuring out who's what. So that's a trend. I am not particularly involved in either of those trends. I already mentioned where I think I'm able to make sort of a contribution, and that's because of my upbringing. I'm a relatively touchy-feely guy for a trauma surgeon. So, I think it's that intersection between touchy-feely human factors and introspective, time-sensitive, high-risk, critical, relatively macho specialty; I don't think there are many people occupying that space. I've sort of accepted that I'm not going to be the guy who redefines fibrinolysis shutdown, where I could help the world tilt in the right direction and do some meaningful work on that other topic (provider stress in hyperacute decision making). What other big trauma topics are there? I think that on the systems level, there's a lot of discussion on the number of trauma centers and where they should be put. There's a recent mandate from the government to better integrate military and civilian trauma during peace time so that military trauma surgeons aren't caught off-guard when there's a conflict because they haven't done any trauma in 10 years. So, that's a lot of work for the future. Right now, roughly speaking, there are too many trauma centers in the city and not enough in the outlying areas and there's the question of whether market forces can work that out or whether big government needs to step in. Those are open questions that people are working through, but there are clearly a lot of gaps in the current setup. When you have too many trauma centers, the experience is diluted, and that becomes very expensive for payors and the quality of care goes down. And then, concomitantly, when there's not enough caregivers in rural settings, obviously the care goes down there, and, paradoxically, the costs go up there too. So, the whole thing is a bad, inefficient system when it's out of tilt like that. And then, again, the military folks are feeling like their system isn't perfect either because they're out of the game unless they're in a war.

General surgery is interesting because I don't know what that really means anymore. The big issue with talking about general surgery these days is that if you pick one of these general surgery textbooks [grabs a textbook off of his shelf], the chapters will include trauma, colorectal surgery, surgical oncology, all of these other things that in a working hospital in an urban center, those are not "general surgery." Those are specialties. So that leaves the fact that there are a few diseases at the center of all that, like bowel obstruction, hernia, simple hernia repair; nobody is really necessarily owning those things, even though those are some of the most important topics and hugely impactful to, especially, an aging American population. So this is kind of built in to the fact that young, academically inclined surgeons feel a pressure to go in to a specialty, and that's what I did. And so, you're not left with people who define themselves as "general surgeons" and make something like dead bowel, bowel obstruction, or necrotizing soft tissue infections their academic and clinical passion. There's kind of a gap in the very center of all these diseases because 
everybody is so camped out in the periphery with their specialty operations. There's this gaping hole in the center of, you know, bright, talented, academically inclined surgeons and scholarly work. 